\title{
Reasons for Sickness Absence: A Review of Medical Certification Data in the Republic of Ireland between 2008 and 2014
}

\author{
Michelle Foley
}

School of Health Sciences, Waterford Institute of Technology, Cork Road, Waterford, Ireland

\begin{abstract}
Background: There is increasing commitment to improve health of working populations in order to reduce the amount of claims for sickness and disability benefits. The aim of this paper was to examine sickness absence trends in the Republic of Ireland as reported by medical certification on the claiming of illness benefit over a seven year period, namely 2008 to 2014 .

Methods: Data were extracted by the Statistical unit of the Department of Social Protection from their central database to include all claims for illness and occupational injury benefit between 2008 and 2014 and presented to the researcher. This data was recoded using broad codes contained in the ICD-10 and combined into a database where summative values were produced under each classification in order to evaluate the average rate of claims per 1000 person employed per year.

Results: A total of 67,021 illness benefit claims were made in 2014 compared to 73,609 in 2008 . When the total workforce was considered this represented a total reduction from 34.2 claims per 1000 person employed (2008) to 30 claims per 1000 employed (2014). Mental and behavioural disorders (FF00-F99) had the highest rate of illness benefit claims resulting in 8.8 claims per 1000 persons employed in 2008 to 8.2 claims per 1000 persons employed in 2014. Disease of the musculoskeletal system and connective tissue (M00-M99) had the second highest rate of claims overall. The most likely reason given under the ICD-code M00-M99 was back/neck/rib and disc problems which accounted for $62.7 \%$ of all claims in the 7 year period. The main reason for occupational injury claims were for injury, poisoning and certain other consequences of external cause (S00-T98) followed by diseases of the musculoskeletal and connective tissue (M00-M99).

Conclusion: Results of this study should be taken into account for future planning of primary healthcare in the Republic of Ireland and for training of GPs in practice.
\end{abstract}

\section{Abbreviations}

\author{
Publication History: \\ Received: May 03, 2016 \\ Accepted: July 23, 2016 \\ Published: July 25, 2016
}

\section{Keywords:}

Medical certification, Sickness certification, Workplace health, Absenteeism, Sickness absence

ROI: Republic of Ireland; GP: General Practitioner; DSP: Department of Social Protection; ICD: International classification of diseases: IB: Illness Benefit; OIB: Occupational Injury Benefit

\section{Introduction}

The health of working populations is of growing interest to all countries in the developed world [1]. Furthermore, governments are increasingly committed to improving the health of working population in order to reduce the amount of claims for sickness and disability benefits [2-4]. In the majority of European countries the level of reported sickness absence is often used as a proxy measure of disease burden [5-7]. In recent times Ireland has become more aware of the importance of sickness absence data and has implemented initiatives such as the Fit for Work strategy to combat and improve the return to work process. Fit for Work Ireland, through their work with key stakeholders from both the work and health arenas, have produced guidelines to help manage and support those working with musculoskeletal disorders in the Irish workplace [8].

Currently, the total cost of sickness absence in the Republic of Ireland (ROI) is not widely reported. Although, it is estimated that work related absence costs the small business sector over 490 million euro per year [9]. While the costs of sickness absence in monetary terms are significant, the indirect costs of 'worklessness' are thought to be much higher and include, poverty, social isolation, increased risk of suicide and greater utilisation of health services, including primary care $[10,11]$. In many countries the role of the General Practitioner (GP) to act as 'gatekeeper' in sickness leave, underscores three main objectives; a need to legitimise the illness, the need to ensure adequate treatment and rehabilitation for the patient and lastly to control the distribution of benefits [12]. In the ROI, GPs are responsible for issuing of sickness certificates, firstly to show that the person's reason for workplace absence is illness related and secondly to enable claims for illness related benefits. Illness benefit (IB) may be claimed from the Department of Social Protection (DSP) if a person is unable to work due to illness for a period of up to 2 years. The requirements for IB is that the patient is under 66 years and satisfies the pay related social insurance (PRSI) conditions [13]. Claims must be made within 7 days of becoming ill. Payment is then made after a waiting period of 6 days. (Note that this was extended from 3 to 6 days from 6 January 2014). The majority of the Irish workforces are deemed eligible for IB in that they earn greater than $€ 38$ per week. However, self-employed persons are not eligible for IB. Occupational Injuries Benefit (OIB) is a related benefit payed to people injured or incapacitated by an accident at work or while travelling directly to or from work. The scheme also covers people who have contracted a disease as a result of the type of work they do. In the case of both IB and OIB, GPs are required to indicate the reason for absence, however some

*Corresponding Author: Dr. Michelle Foley, School of Health Sciences, Waterford Institute of Technology, Cork Road, Waterford, Ireland, Tel: +35351 845593; E-mail: mfoley@wit.ie

Citation: Foley M (2016) Reasons for Sickness Absence: A Review of Medica Certification Data in the Republic of Ireland between 2008 and 2014. Int J Community Fam Med 1: 112. doi: http://dx.doi.org/10.15344/ijcfm/2016/112

Copyright: (c) 2016 Foley. This is an open-access article distributed under the terms of the Creative Commons Attribution License, which permits unrestricted use, distribution, and reproduction in any medium, provided the original author and source are credited. 
Citation: Foley M (2016) Reasons for Sickness Absence: A Review of Medical Certification Data in the Republic of Ireland between 2008 and 2014. Int J Community Fam Med 1: 112. doi: http://dx.doi.org/10.15344/ijcfm/2016/112

Page 2 of 6

evidence suggests that GPs remain unware of the levels of sickness absence in the working population and are therefore unable to respond appropriately or influence policy. The current system is not coded directly under the International Classification of Disease (ICD), although some broad categories are used in current reporting.

The aim of this paper was to examine sickness absence trends in the ROI as reported by medical certification on the claiming of IB over a seven year period, namely 2008 to 2014 . The main outcome measure was to identify the most frequent causes of illness resulting in absence from work using the ICD-10 criteria. A secondary objective was to examine the most frequent causes of occupational related illness resulting in sickness absence in the Irish workplace.

\section{Materials and Method}

\section{Study population}

The study population included all persons that made a claim for illness related benefits during specified years 2008 and 2014 inclusive. For this study the data were extracted by the Statistical unit of the DSP from their central database to include all claims for illness and occupational injury benefit between 2008 and 2014. The GP must issue and sign the medical certificate $(\mathrm{MC1})$ and the patient is required to complete personal details including public service numbers, gender, age, marital status and income levels to claim benefits. Occupational illness data must include additional information detailing the accident or injury incurred and this must be witnessed and co-signed by the employer. This data is then entered for the processing of illness benefit payments and is electronically recorded at the DSP. prevalence) [14], the total employed workforce for each independent year was used as a denominator (obtained from the Central Statistics Office (CSO) (Table 1). This produced a rate of claims per 1000 persons employed per year. Data was tabulated to illustrate trends in benefit claims for illness over time. Due to the low number of occupational related reported cases, the data were prepared to illustrate the highest reported conditions under the ICD-10. The data was displayed graphically to show trends in OIB claims over time (2008-2014). Claims that could not be classified under the ICD-10, (for example surgery/incapacity/illegible) were reclassified as other.

The two main categories accounting for the highest proportion of illness benefit claims were subdivided into specific illness type and examined across the seven year period. The illness type was then calculated as a proportion of those presenting and being certified with the condition for each independent year.

\section{Results}

A total of 67,021 illness benefit claims were made in 2014 and this compared to 73,609 in 2008 . When the total workforce is considered this represents a total reduction from 34.2 claims per 1000 person employed (2008) to 30 claims per 1000 employed (2014). Figure 1 illustrates the top five illness reported as a percentage of the total number of claims from 2008-2014. Table 2 illustrates the rate of illnesses benefit claims per 1000 persons employed per year. Mental and behavioural disorders (FF00-F99) had the highest rate of illness benefit claims year on year. Overall a slight decrease of $6.8 \%$ was observed from 2008 (8.8 claims per 1000 persons employed) to

\begin{tabular}{|c|c|c|c|c|c|c|c|}
\hline Year & 2008 & 2009 & 2010 & 2011 & 2012 & 2013 & 2014 \\
\hline \multicolumn{8}{|c|}{ Persons in labour force } \\
\hline In Employment (000) & 2,147 & $1,974.0$ & $1,893.6$ & $1,861.3$ & $1,836.2$ & $1,869.9$ & $1,901.6$ \\
\hline Unemployed (000) & 226 & 423 & 452 & 447 & 437 & 419 & 382 \\
\hline \multicolumn{8}{|c|}{$\begin{array}{l}\text { Employment rate \% } \\
\text { person age 15-64 years }\end{array}$} \\
\hline All persons & 67.9 & 62.2 & 60 & 59.2 & 58.8 & 60.2 & 61.3 \\
\hline Male & 75.4 & 66.8 & 63.9 & 62.8 & 62.4 & 64.6 & 56.4 \\
\hline Female & 60.4 & 57.6 & 56.0 & 55.6 & 55.2 & 55.9 & 61.3 \\
\hline
\end{tabular}

\section{Data analysis}

This data was presented to the researcher as an Excel $^{\circ}$ file following a data request under the freedom of information act 2014. The data included all claims awarded and in payment at each individual year end grouped by 227 illness categories. Information on the demographics of claimants (gender and age) was also provided along with information on total expenditure. Data were examined and recoded by the researcher using broad codes contained in the ICD10. For example, if back pain was indicated as the cause of absence on the medical certificate then this was reclassified under disease of the musculoskeletal system (M00-M99). When all coding was completed $10 \%$ of the coded data was rechecked to ensure accuracy. A random numbers list was generated (based on the 227 categories) and 23 records were extracted for each year and checked against the ICD code assigned. No errors in coding were found. Data were then combined into a database and summative values were produced under each classification. To evaluate the average rate of claims (i.e period
2014 (8.2 claims per 1000 persons employed). When further analysed, anxiety and depression accounted for $49.5 \%$ of claims and stress accounted for $24.2 \%$ over the seven year period. Figure 2 shows trends in claims under each specific category of illness F00-F99 from 2008 - 2014. Disease of the musculoskeletal system and connective tissue (M00-M99) had the second highest rate of claims. Similarly, a decrease was observed in claims over the seven year period from 7.6 per 1000 person employed to 6.6 per 1000 person employed. Figure 3 illustrates the most likely reason for certification under the ICD-code M00-M99 (2008-2014). Back/neck/rib and disc problems accounted for $62.7 \%$ of all illness benefit claims when combined over the 7 year period. This was followed by arthritic conditions (rheumatism and osteoarthritic (OA)) at $19.5 \%$. Medical certificates that could not be classified under ICD-10 accounted for $12.5 \%$ of the total claims for IB. This figure was consistent across each year from 2008-2014.

The total number of claims for occupational injury was similar across the seven year period. The principal reasons for occupational 
Citation: Foley M (2016) Reasons for Sickness Absence: A Review of Medical Certification Data in the Republic of Ireland between 2008 and 2014. Int J Community Fam Med 1: 112. doi: http://dx.doi.org/10.15344/ijcfm/2016/112

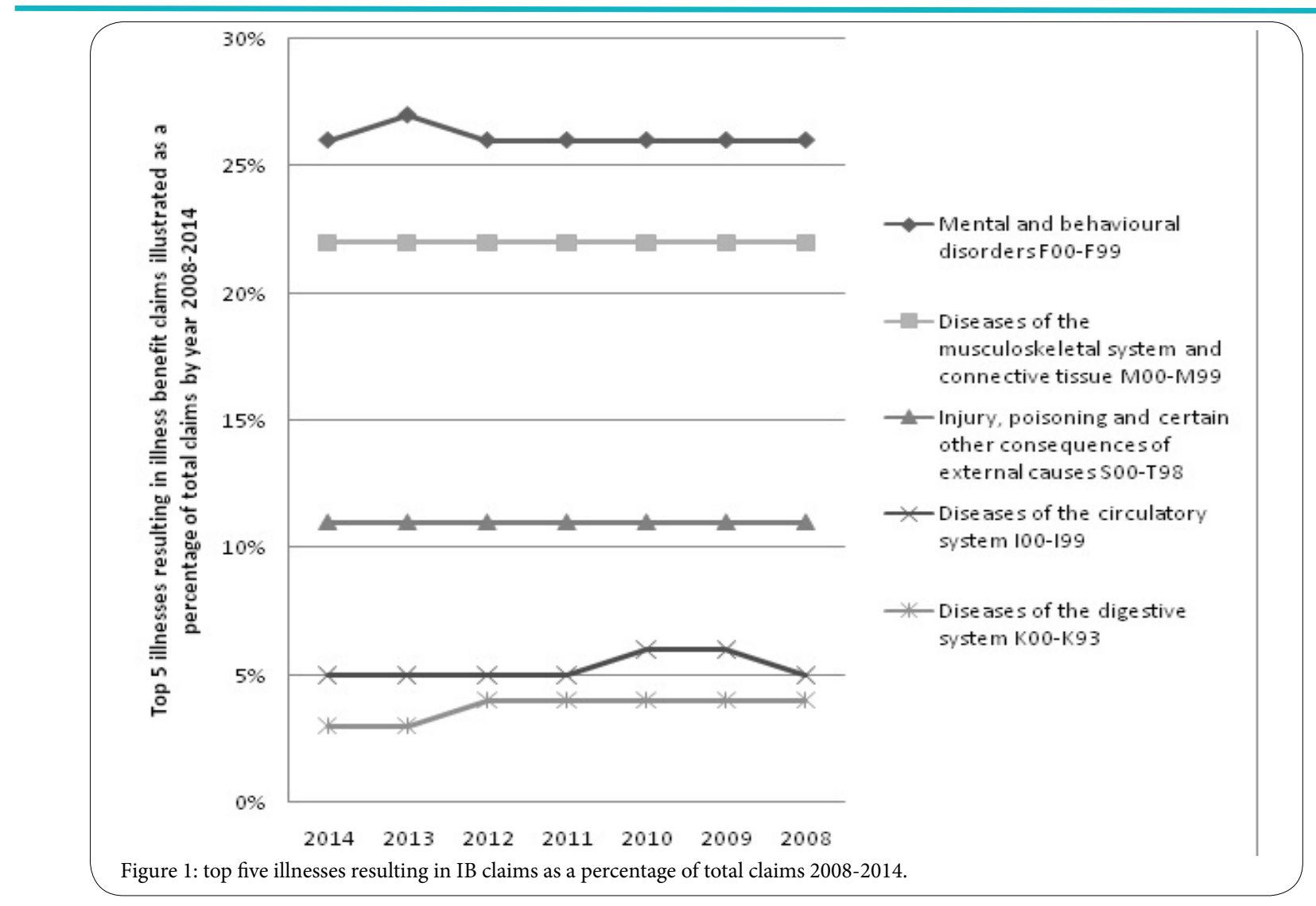

\begin{tabular}{|c|c|c|c|c|c|c|c|c|}
\hline Year of Claim & & 2008 & 2009 & 2010 & 2011 & 2012 & 2013 & 2014 \\
\hline Classification & ICD-10 code & & & & & & & \\
\hline Certain infectious and parasitic diseases & A00-B99 & 0.77 & 0.87 & 0.79 & 0.78 & 0.69 & 0.60 & 0.56 \\
\hline Neoplasms & C00-D48 & 0.62 & 0.78 & 0.96 & 0.99 & 1.00 & 0.87 & 0.84 \\
\hline $\begin{array}{l}\text { Diseases of the blood and blood-forming organs and certain } \\
\text { disorders involving the immune mechanism }\end{array}$ & D50-D89 & 0.32 & 0.29 & 0.28 & 0.23 & 0.20 & 0.18 & 0.16 \\
\hline Endocrine, nutritional and metabolic diseases & E00-E90 & 0.40 & 0.46 & 0.52 & 0.44 & 0.40 & 0.35 & 0.30 \\
\hline Mental and behavioural disorders & F00-F99 & 8.8 & 10.1 & 11.0 & 10.2 & 9.13 & 8.4 & 8.2 \\
\hline Diseases of the nervous system & G00-G99 & 0.76 & 0.88 & 0.98 & 0.96 & 0.87 & 0.79 & 0.76 \\
\hline Diseases of the eye and adnexa & H00-H59 & 0.11 & 0.15 & 0.15 & 0.14 & 0.15 & 0.13 & 0.12 \\
\hline Diseases of the ear and mastoid process & H60-H95 & 0.12 & 0.13 & 0.14 & 0.12 & 0.11 & 0.10 & 0.09 \\
\hline Diseases of the circulatory system & I00-I99 & 1.87 & 2.25 & 2.46 & 2.15 & 1.8 & 1.4 & 1.36 \\
\hline Diseases of the respiratory system & J00-J99 & 1.18 & 1.33 & 1.31 & 1.22 & 1.08 & 0.91 & 0.83 \\
\hline Diseases of the digestive system & K00-K93 & 1.27 & 1.41 & 1.56 & 1.41 & 1.23 & 1.09 & 1.02 \\
\hline Diseases of the skin and subcutaneous tissue & L00-L99 & 0.24 & 0.27 & 0.29 & 0.27 & 0.24 & 0.23 & 0.23 \\
\hline Diseases of the musculoskeletal system and connective tissue & M00-M99 & 7.6 & 8.7 & 9.7 & 8.8 & 7.8 & 6.9 & 6.6 \\
\hline Diseases of the genitourinary system & N00-N99 & 0.47 & 0.52 & 0.56 & 0.50 & 0.44 & 0.41 & 0.39 \\
\hline Pregnancy, childbirth and the puerperium & O00-O99 & 1.0 & 1.2 & 1.2 & 1.1 & 1.0 & 0.94 & 0.84 \\
\hline Certain conditions originating in the perinatal period & P00-P96 & \multicolumn{7}{|l|}{ No claimantsindicated } \\
\hline $\begin{array}{l}\text { Congenital malformations, deformations and chromosomal } \\
\text { abnormalities }\end{array}$ & Q00-Q99 & 0.01 & 0.01 & 0.01 & 0.01 & 0.01 & 0.01 & 0.01 \\
\hline $\begin{array}{l}\text { Symptoms, signs and abnormal clinical and laboratory } \\
\text { findings, not elsewhere }\end{array}$ & R00-R99 & 0.67 & 0.79 & 0.85 & 0.80 & 0.74 & 0.67 & 0.65 \\
\hline $\begin{array}{l}\text { Injury, poisoning and certain other consequences of external } \\
\text { causes }\end{array}$ & S00-T98 & 3.6 & 4.2 & 4.6 & 4.2 & 3.8 & 3.5 & 3.3 \\
\hline External causes of morbidity and mortality & V01-Y98 & \multicolumn{7}{|l|}{ No claimants indicated } \\
\hline $\begin{array}{l}\text { Factors influencing health status and contact with health } \\
\text { services }\end{array}$ & Z00-Z99 & \multicolumn{7}{|l|}{ No claimants indicated } \\
\hline Codes for special purposes & U00-U99 & \multicolumn{7}{|l|}{ No claimants indicated } \\
\hline
\end{tabular}


Citation: Foley M (2016) Reasons for Sickness Absence: A Review of Medical Certification Data in the Republic of Ireland between 2008 and 2014. Int J Community Fam Med 1: 112. doi: http://dx.doi.org/10.15344/ijcfm/2016/112

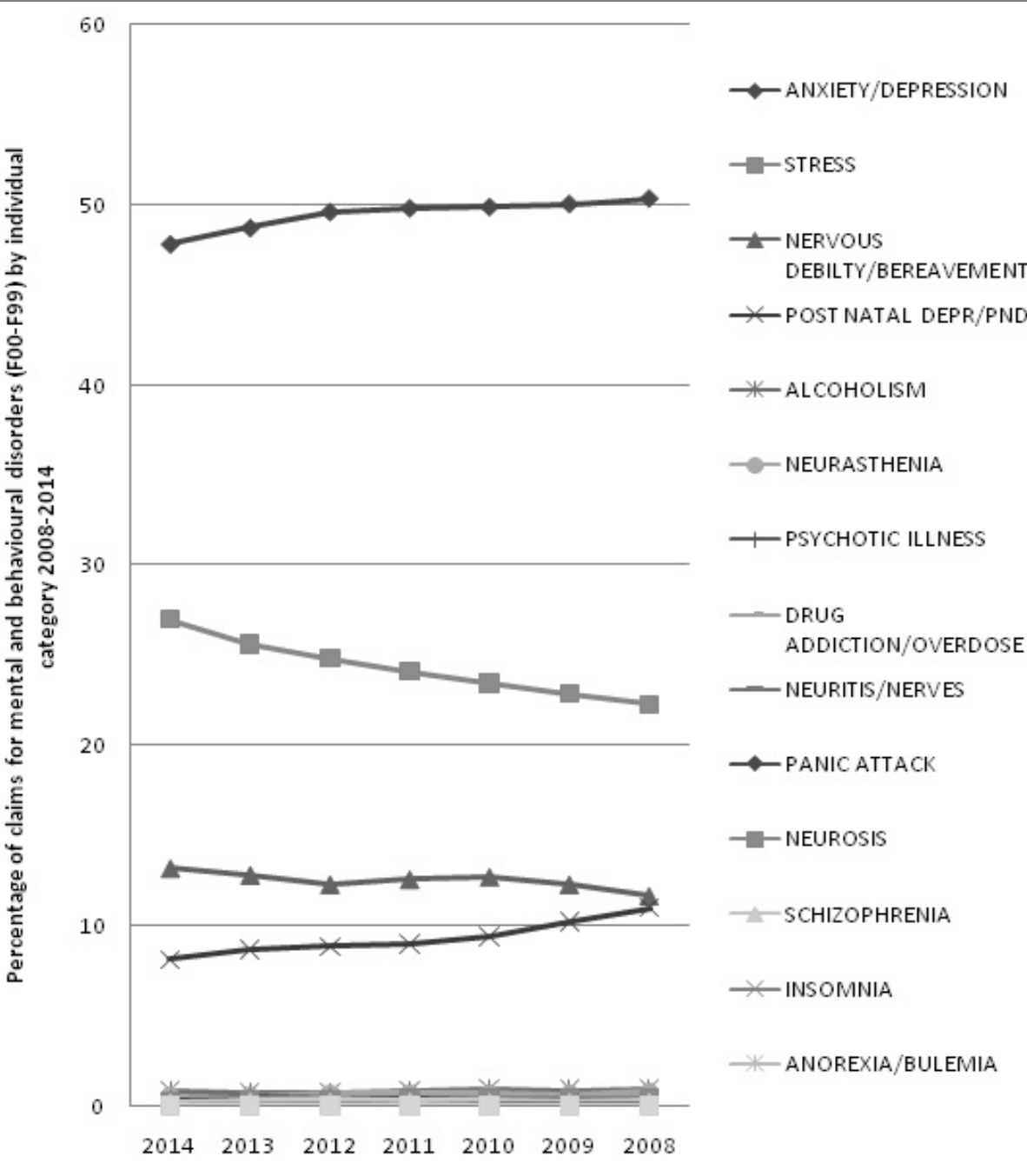

Figure 2: Reason for illness benefit claims by Mental and behavioural disorders.

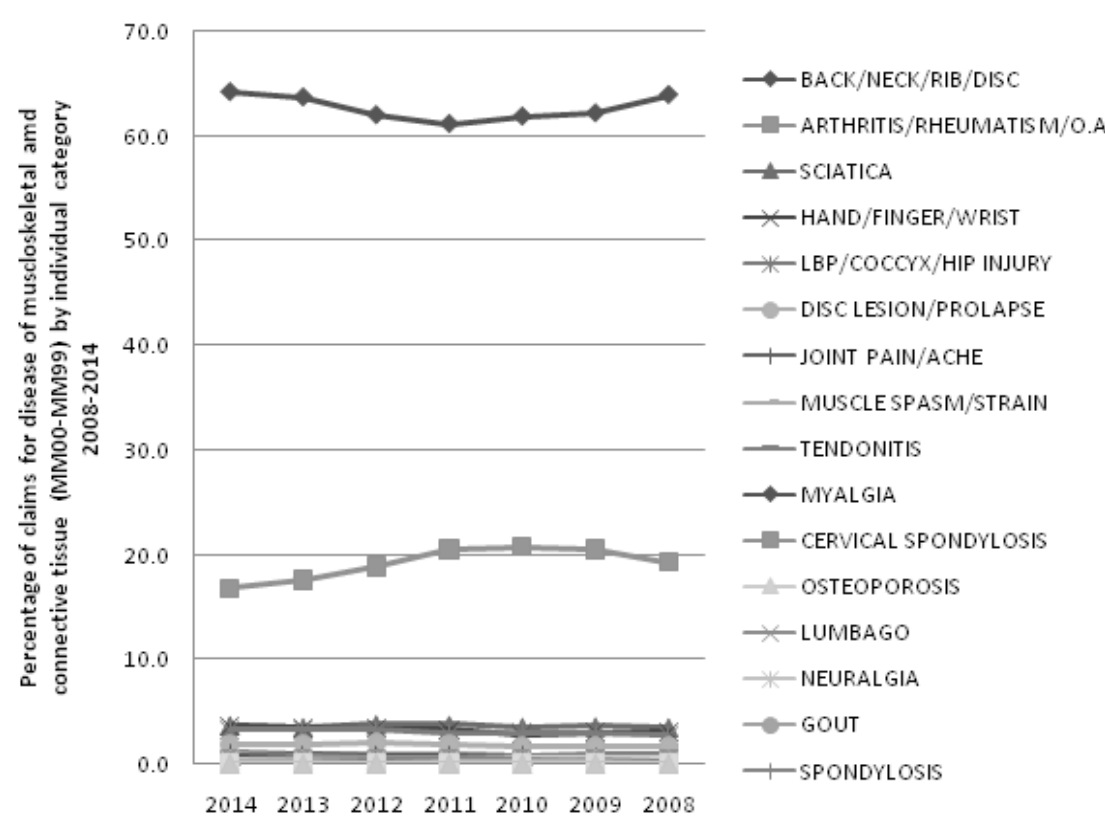

Figure 3: Reasons for illness benefit claims for disease of musculoskeletal and connective tissue. 
Citation: Foley M (2016) Reasons for Sickness Absence: A Review of Medical Certification Data in the Republic of Ireland between 2008 and 2014. Int J Community Fam Med 1: 112. doi: http://dx.doi.org/10.15344/ijcfm/2016/112

Page 5 of 6

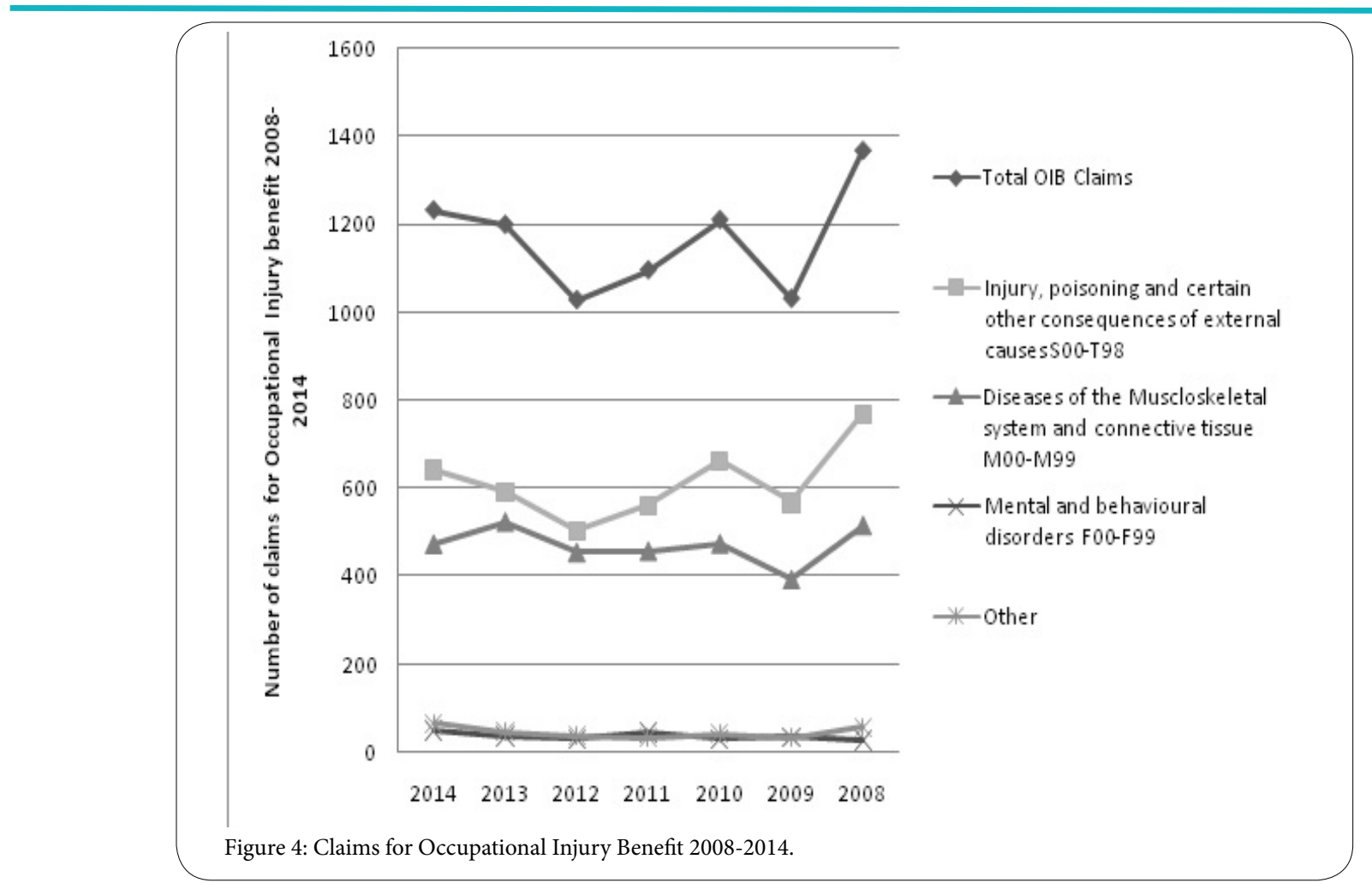

injury claims were for injury, poisoning and certain other consequences of external cause (S00-T98) followed by diseases of the musculoskeletal and connective tissue (M00-M99). Both conditions account for over $85 \%$ of the total claims for OIB. Figure 4 shows the trends in claimsover 2008-2014. On further examination of the data breaks, fractures and injuries to the lower extremities (leg, ankle and knee) were the most likely cause of OIB claims and accounted for $60 \%$ of the total claims under the category S00-T98. Claims for back, neck, rib and disc (74\%) were most likely under the classification for musculoskeletal and connective tissue (M00-M99). Occupational stress accounted for just 23 claims in 2008 and 38 in 2014.

\section{Discussion}

In this research, the rate of claims for IB was examined in each yearly period over a seven year time frame. The data presented shows that the most frequent cause of work related absence as reported by GPs under the IB scheme is mental and behaviour disorders followed by diseases of the musculoskeletal system and connective tissue. The high level of sickness certification for both musculoskeletal and mental health related problems present a worrying trend for GPs, employers, benefit agencies and public health. Emerging evidence from other countries is that conditions such as musculoskeletal and mental health related problems pose particular difficulties for certifying GPs due to limited measurable pathology $[15,16]$. Research suggests that GPs must often rely on the patient's own assessment of functional capacity to work $[17,18]$. Indeed, concerns have been raised in relation to the skills of doctors in managing fitness for work, their knowledge of a patient's working tasks [19]. Recent research conducted with GPs workings in the ROI also supports these findings [20,21]. The benefits of work are widely recognised and in particular for those with mental health related conditions. In recent times efforts have been made across Europe to improve the reporting of illness to employers so that reasonable adjustment can be made to facilitate employees to remain in the workplace. For example, in the United Kingdom (UK) the 'Fit note' has been recently introduced and is aimed as stating what the employee can do rather than what they are unable to do [22]. In a recent study of 198 Irish GPs, 53\% indicated preference for the introduction of a fit note and cited lack of rehabilitation service as one of the main factors impacting on patients return to work [23].

Although there appears to be a decreasing trend in overall individual claimants over the period, this is most likely as a result of changes in the recent waiting period of 3 to 6 days for claiming illness benefit and the current economic conditions $[13,24]$. At present, there appears to be no clear role within the Department of Health in the ROI in use of sickness certification data in determining healthcare utilisation resourcing and planning. This presents a void. One recommendation following the evaluation of this data is that current disease reporting contained within the medical certificate could be easily adjusted to follow the ICD codes and used as a comparative measure both nationally and internationally [25]. This disease reporting could be used to inform policy on work practices identifying the most at risk groups and prevention activities and equally the allocation of resources to help GPs in practice with managing fitness for work matters. The co-signing of a medical certificate for OIB is also likely to act as a deterrent for some employers due to fear of litigation $[20,26]$. Figures from the Occupational reporting network (THOR-GP) in the UK suggest much higher incidences of work related mental ill health in comparison to those seen in the Irish workforce [27]. It is likely that work is a contributory factor in many illness benefit claims and failure to recognise or acknowledge the impact of work on development of certain disease may limit preventative measures.

There are a number of limitations in respect to this data. Not all people are eligible to claim illness or occupational injury benefit and exclude those working in self-employment. Distinction cannot be made between self-employment and employed persons in the calculation of the total workforce figures which leads to some inaccuracies in the data. Some illnesses were recorded as surgery/ 
Citation: Foley M (2016) Reasons for Sickness Absence: A Review of Medical Certification Data in the Republic of Ireland between 2008 and 2014. Int J Community Fam Med 1: 112. doi: http://dx.doi.org/10.15344/ijcfm/2016/112

Page 6 of 6

incapacity/illegible and therefore could not be coded under the ICD10. Data excludes all short term illness that is illness of duration of less than three days between 2008-2104 and six days 2014. This data set cannot be fully scrutinised by gender, age and occupation and although this information is gathered by the DSP it is not available in a suitable format (anonymised individual records) for subgroupanalysis.

\section{Conclusion}

Despite the limitation outlined this study provides valuable and useful information for the healthcare system and for policy makers and shows that data collected from illness benefit claims is useful. Results of this study should be taken into account for future planning of primary healthcare in the Republic of Ireland and for training of GPs in practice. The majority of claims for illness benefits are associated with diseases of the musculoskeletal system and mental health conditions and are comparable with trends in other industrialised countries. However, additional resources to help facilitate the return to work process could include physiotherapy, counselling services and occupational health support [23]. The introduction of a certification system that allows for adapted work practices such as reduced work hours or alternative duties may help GPs and employers to facilitate early return to work or allow the person to remain within the workplace during their spell of illness. Similar practices have been introduced in the UK through the 'fit note' initiative and this now needs to be given full considered in Ireland. While the role of GPs in acting as gatekeepers for the DSP may have practicalities in a broader sense it may not be sufficient in the requirement to act as an 'expert' in assessment of fitness for work. The debate needs to focus on role of GPs in the delivery of workplace health and how this role can be adapted in the future to improve the health of the working population.

\section{Competing Interests}

The authors declare that they have no competing interests.

\section{References}

1. Knudsen AK, Harvey SB, Mykletun A, Øverland S (2013) Common menta disorders and long term sickness absence in a general working population. The Hordaland Health Study. Acta Psychiatrica Scandinavica 127: 287-97.

2. Nielsen MBD, Hansen JV, Aust B, Tverborgvik T, Thomsen BL, et al. (2015) A multisite randomized controlled trial on time to self-support among sickness absence beneficiaries. The Danish national return-to-work programme. Eur Journal of Public Health 25: 96-102.

3. Black DC (2012) Work, Health and Wellbeing. Saf health work 3: 241.

4. Mody GM, Brooks PM (2012) Improving musculoskeletal health: Global issues. Best Pract Res Clin Rheumatol 26: 237-249.

5. Leijon O, Josephson M, Österlund N (2015) Sick-listing adherence: a register study of 1.4 million episodes of sickness benefit 2010-2013 in Sweden. BMC public health15: 1 .

6. Gimeno D, Benavides FG, Benach J, Amick BC (2004) Distribution of sickness absence in the European Union countries. Occupational and Environmental Medicine 61: 867-869.

7. Kivimäki M, Head J, Ferrie JE, Shipley MJ, Vahtera J, et al. (2003) Sickness absence as a global measure of health: evidence from mortality in the Whitehall II prospective cohort study. BMJ 327: 364.

8. Arthritis Ireland (2015) Working with arthritis, back pain \& related conditions: A guide for employees. In: Arthritis Ireland, Dublin.

9. Small Firms Association (2015) Absence costs small business over $€ 490$ million per annum.

10. Fishwick D, Lunt J, Curran AD, Trainor M (2010) Well-being and work: A perspective from eight European countries on common areas of understanding, national drivers for progress, and research needs. PROCEE 2010: 118
11. Braun T, Bambra C, Booth M, Adetayo K, Milne E (2014) Better health at work? An evaluation of the effects and cost-benefits of a structured workplace health improvement programme in reducing sickness absence. J Public Health(oxf) 37: 138-142.

12. Willems $D$ (2001) Balancing rationalities: gatekeeping in health care. J Med Ethics 27: 25-29.

13. Department of Social Protection, illness benefit Dublin 2016

14. Fletcher RH, Fletcher SW, Fletcher GS (2012) Clinical epidemiology: the essentials: Lippincott Williams \& Wilkins; 2012

15. Winde LD, Alexanderson K, Carlsen B, Kjeldgård L, Wilteus AL, et al. (2012) General practitioners' experiences with sickness certification: a comparison of survey data from Sweden and Norway. BMC Family Practice 13: 1.

16. Norrmén G, Svärdsudd K, Andersson DK (2008) How primary health care physicians make sick listing decisions: The impact of medical factors and functioning. BMC Fam Pract 9: 1.

17. Reiso H, Nygard JF, Brage S, Gulbrandsen P, Tellnes G (2000) Work ability assessed by patients and their GPs in new episodes of sickness certification. Fam Pract 17: 139-44.

18. Von Knorring M, Sundberg L, Löfgren A, Alexanderson K (2008) Problems in sickness certification of patients: a qualitative study on views of 26 physicians in Sweden. Scandinavian journal of primary health care. Scan J Pub Health 26: 22-28.

19. Söderberg E, Alexanderson K (2003) Sickness certification practices of physicians: a review of the literature. Scand J Public Health 31: 460-474

20. Foley M, Thorley K, Denny M (2012) 'The sick note': A qualitative study of sickness certification in general practice in Ireland. Eur J Gen Pract 18: 92-99.

21. Foley M, Thorley K, Von Hout MC (2013) Sickness certification difficulties in Ireland--GP focus group study. Occup Med 63: 369-372.

22. Wainwright $E$, Wainwright $D$, Keogh $E$, Eccleston $C$ (2011) Fit for purpose? Using the fit note with patients with chronic pain: a qualitative study. $\mathrm{Br} J$ Gen Pract 61: e794-e800

23. King R, Murphy R, Wyse A, Roche E (2016) Irish GP attitudes towards sickness certification and the 'fit note'. Occupational Medicine 66: 150-155.

24. Vossen E, van Gestel N (2015) The activation logic in national sickness absence policies: Comparing the Netherlands, Denmark and Ireland. European Journal of Industrial Relations 21: 165-180.

25. Barmby TA, Ercolani MG, Treble JG (2002) Sickness absence: an international comparison. The Economic Journal 112: F315-F31.

26. Young AE, Choi Y, Besen E (2015)An Exploration of the Factors Considered When Forming Expectations for Returning to Work following Sickness Absence Due to a Musculoskeletal Condition. PloS one 10: e0143330.

27. Hussey L (2015) THOR-GP input to HSE Annual Statistics 2014/2015 - Note on methods used for calculating incidence rates and 'caveats' in interpretation. Manchester: University of Manchester. 